\title{
Transient Cystoid Macular Oedema in Multiple Choroidal Naevi
}

\author{
Kimia Ziahosseini* and Ahmed Kamal
}

Department of Ophthalmology, Aintree University Hospital, Liverpool, Longmoor Lane, L9 7AL, UK

\begin{abstract}
Choroidal Naevi are generally thought to be trivial. However, sometimes they cause visual loss, visual filed defect and rarely transform into malignant melanoma. We report the first case of unilateral numerous choroidal naevi in a healthy female associated with transient cystoid macular oedema and postulate about its pathogenesis.
\end{abstract}

Keywords: Choroidal naevus, macular oedema, cystoid macular oedema.

\section{CASE-REPORT}

A 48-year-old female presented with three weeks history of left eye blurred vision. She had no previous ophthalmic or medical problems and was not on any medications. Visual acuity (VA) at presentation was 6/5 right and 6/9 left eye. External ocular and anterior segment examination was normal. Dilated funduscopy of left eye showed numerous flat, pigmented choroidal lesions with indistinct border suggestive of choroidal naevi in the posterior pole and inferior retina with cystoid macular oedema (CMO) (Fig. 1). Fluorescein angiography confirmed CMO with retinal capillary leakage (Fig. 2). Right eye was normal. years later, She remains well, choroidal naevi are unchanged and $\mathrm{VA}$ is $6 / 5 \mathrm{OU}$.

\section{DISCUSSION}

CMO represents the common final pathway of a heterogenous group of processes. The tight junctions between retinal pigment epithelial cells (RPE) and retinal capillary endothelial cells can be disturbed in disease process and by cytokines [1].

Choroidal naevi can induce histologic changes in their neighbouring tissues such as narrowing or complete

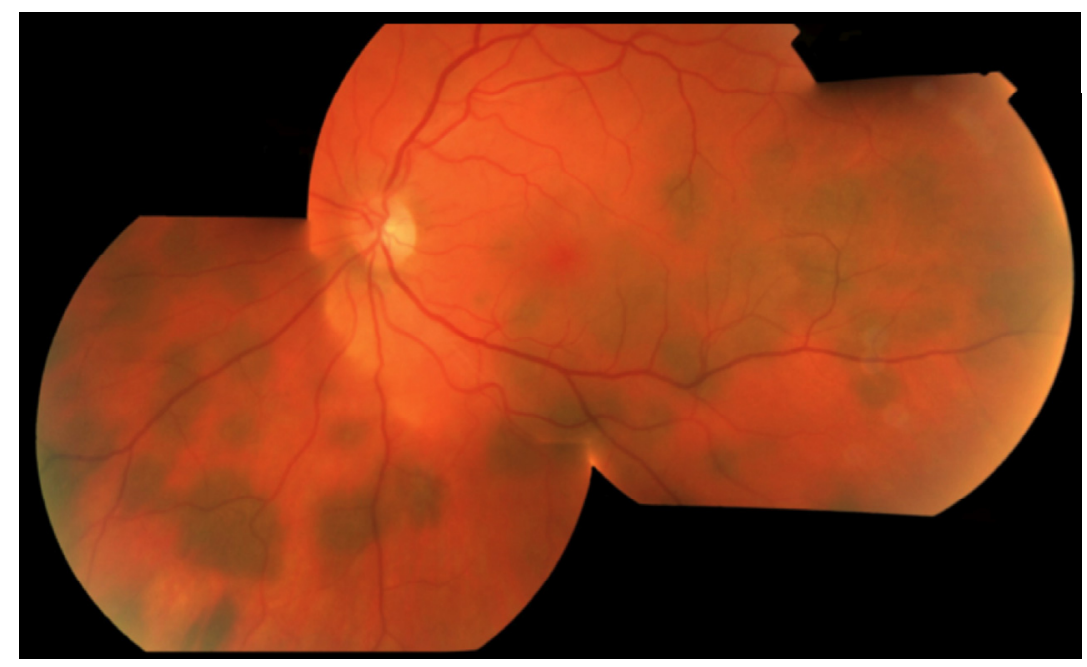

Fig. (1). Coluor fundus photograph of left eye showing numerous choroidal naevi.

Examination and investigations by a physician to exclude systemic malignancy were normal. Laboratory tests and electrodiagnostic tests were normal. Six months later, CMO resolved spontaneously and VA improved to 6/5. Six

*Address correspondence to this author at the Department of Ophthalmology, Aintree University Hospital, Liverpool, Longmoor Lane, L9 7AL, UK; Tel: 0151529 0146; Fax: 0151529 0139;

E-mail: kim.z@doctors.org.uk obliteration of the choriocapillaris, degeneration or proliferation of RPE and photoreceptors disturbances [2]. Shield et al. have reported on the presence of retinal oedema overlying a choroidal naevus with associated RPE/choriocapillaris irregularities in $15 \%$ of their patients when examined with Optical coherence tomography (OCT) [3].

Multiplicity of choroidal naevi to this extent is unusual. Shield et al. reported a maximum of 10 naevi in less than $1 \%$ of their 3422 studied eyes [4]. 


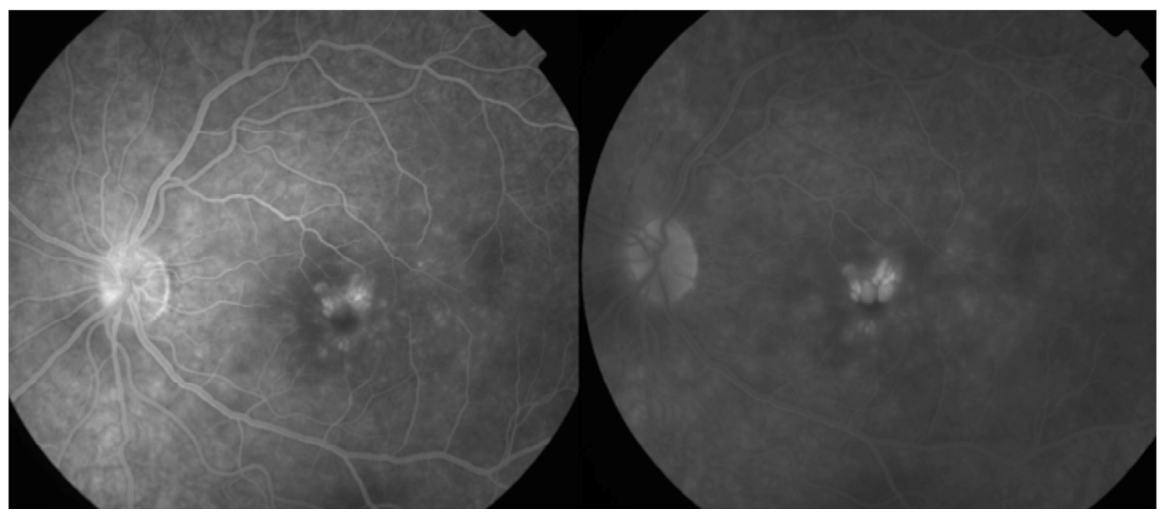

Fig. (2). Right; shows retinal capillary leakage on fluorescein angiography of the left eye. Left; shows late phase fluorescein angiography with $\mathrm{CMO}$.

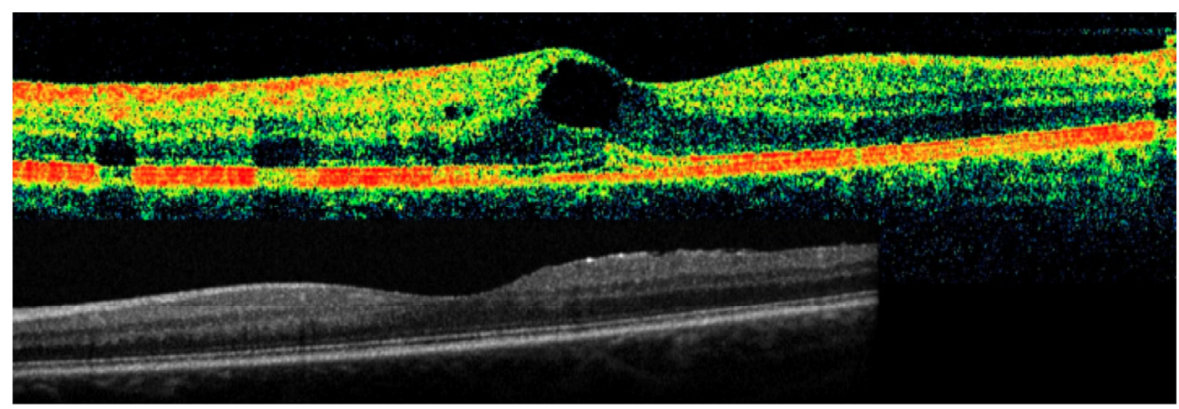

Fig. (3). Top; Stratus OCT through fovea shows CMO. Bottom; HRA OCT through fovea showing absence of RPE/photoreceptor layers irregularities following resolution of CMO.

Multiple naevus-like lesions as a result of proliferation of benign melanocytes in the outer choroid occur in bilateral diffuse uveal melanocytic proliferation. It is a very rare paraneoplastic syndrome occurring in elderly patients with advanced systemic malignancy [5]. This case's clinical picture and outcome are clearly different from this condition.

In this patient, choroidal naevi were scattered in the parafoveal and peripheral retina but spared the fovea. Spectral domain OCT did not show any disturbance of overlying RPE and photoreceptor layer (Fig. 3). There were no other pathologic findings to explain the CMO. In the absence of detectable changes in RPE and photoreceptor layers, we postulate that altered cytokine milieu might have caused the CMO and its subsequent resolution. Nevertheless, unilateral or bilateral macular oedema may occur with no identifiable cause. In some idiopathic cases the oedema may resolve spontaneously or in some others persist despite treatment [6]. Although this case may belong to this category, one would naturally like to speculate about the pathogenesis of unilateral macular oedema in such a rare condition.

\section{CONFLICT OF INTEREST}

The authors confirm that this article content has no conflicts of interest.

\section{ACKNOWLEDGEMENTS}

Declared none.

\section{REFERENCES}

[1] Funatsu H, Yamashita H, Ikeda T, et al. Vitreous levels of interleukin-6 and vascular endothelial growth factor are related to diabetic macular edema. Ophthalmology 2003; 110:1690-6.

[2] Naumann G, Yanoff M, Zimmerman L. Histogenesis of malignant melanomas of the uvea: histopathologic characteristics of nevi of the choroid and ciliary body. Arch Ophthalmol 1966; 6: 784-96.

[3] Shields CL, Mashayekhi A, Materin MA, et al. Optical coherence tomography of choroidal nevus in 120 patients. Retina 2005; 25(3): 243-52.

[4] Shields CL, Furuta M, Mashayekhi A, et al. Clinical spectrum of choroidal nevi based on age at presentation in 3422 consecutive eyes. Ophthalmology 2008; 115(3): 546-52.

[5] Gass J, Geiser R, Wilkinson C, et al. Bilateral diffuse uveal melanocytic proliferation in patients with occult carcinoma. Arch Ophthalmol 1990; 108:527-33.

[6] Johnson MW. Etiology and treatment of macular edema. Am J Ophthalmol 2009; 147(1): 11-21. 